\title{
RANDOMISED CONTROLLED STUDY OF 0.5\% ISOBARIC LEVOBUPIVACAINE PLUS FENTANYL WITH 0.75\% ISOBARIC ROPIVACAINE PLUS FENTANYL IN SPINAL ANAESTHESIA FOR TRANSURETHRAL RESECTION OF PROSTATE (TURP) SURGERIES
}

\author{
Kothakoona Srilakshmi1, Kallepalli Kurmanadh²
}

${ }^{1}$ Associate Professor, Department of Anaesthesiology, Andhra Medical College, Visakhapatnam, Dr. NTR University of Health Sciences, Vijayawada.

${ }^{2}$ Associate Professor, Department of Anaesthesiology, Andhra Medical College, Visakhapatnam, Dr. NTR University of Health Sciences, Vijayawada.

\section{ABSTRACT}

\section{BACKGROUND}

The current gold standard surgical treatment for Benign Prostatic Hyperplasia (BPH) is Transurethral Resection of Prostate (TURP). TURP is the $2^{\text {nd }}$ most common procedure in men over 65 years of age. The procedure usually takes 30 - 90 mins. Regional anaesthesia is the technique of choice for TURP. Ropivacaine and Levobupivacaine, both being S-enantiomers of Bupivacaine have similar duration of sensory and motor blockade as racemic Bupivacaine, but having safe cardiovascular profile.

The aim of the study was, this study was conducted to compare a combination of $0.75 \%$ isobaric Ropivacaine with fentanyl 25 mcg and combination of $0.5 \%$ isobaric levobupivacaine with fentanyl 25 mcg as spinal anaesthetic for TURP surgery. Fentanyl when used as an adjuvant for spinal anaesthesia has a local anaesthetic sparing effect with profound and prolonged analgesia without significantly affecting the level of blockade, which is important in TURP surgeries.

\section{MATERIALS AND METHODS}

The study intended to compare the efficacy of $0.5 \%$ levobupivacaine plus Fentanyl and 0.75\% Ropivacaine plus Fentanyl in Transurethral Resection of Prostate (TURP) surgeries. The prospective, randomised and comparative study was conducted from April 2014 to March 2015 at King George Hospital, Visakhapatnam, Andhra Pradesh, affiliated to Andhra Medical College. Elderly male patients between 50 - 75 years of age with ASA status 1 to 3 are taken up for the study.

\section{RESULTS}

$0.5 \%$ isobaric Levobupivacaine $(12.5 \mathrm{mg}$ ) and Fentanyl (25 mcg) combination produced faster onset, prolonged and similar level of sensory blockade, prolonged duration of motor blockade compared to 0.75\% isobaric Ropivacaine (18.75 mg) and Fentanyl (25 $\mathrm{mcg}$ ) combination in adult patients undergoing elective TURP surgeries without significant haemodynamic changes.

\section{CONCLUSION}

0.75\% Ropivacaine plus Fentanyl combination can be a better drug for TURP surgeries compared to Levobupivacaine plus Fentanyl combination, because of shorter duration of action and faster regression of motor blockade.

\section{KEYWORDS}

Spinal Anaesthesia, Transurethral Resection of Prostate, Fentanyl, Ropivacaine, Levobupivacaine.

HOW TO CITE THIS ARTICLE: Srilakshmi K, Kurmanadh K. Randomised controlled study of 0.5\% isobaric levobupivacaine plus fentanyl with $0.75 \%$ isobaric ropivacaine plus fentanyl in spinal anaesthesia for Transurethral Resection of Prostate (TURP) surgeries. J. Evolution Med. Dent. Sci. 2017;6(15):1189-1192, DOI: 10.14260/Jemds/2017/259

\section{BACKGROUND \\ For decades the ${ }^{1}$ local anaesthetic of choice for spinal anaesthesia is Lidocaine. Its advantages are rapid onset of action and good motor block manifested as good muscle relaxation. Its use however is limited by its short duration of action and its implication in transient neurologic symptoms and cauda equina syndrome following intrathecal injection. Bupivacaine is three to four times more potent than lidocaine and has longer duration of action. Its disadvantages are slow}

Financial or Other, Competing Interest: None.

Submission 30-01-2017, Peer Review 11-02-2017,

Acceptance 13-02-2017, Published 20-02-2017.

Corresponding Author:

Dr. Kothakoona Srilakshmi,

Associate Professor,

Department of Anaesthesiology,

Andhra Medical College,

Visakhapatnam, Andhra Pradesh.

E-mail:dr.ksl.md@gmail.com

DOI: $10.14260 /$ jemds $/ 2017 / 259$ onset of action and decreased motor block. ${ }^{2}$ Bupivacaine is a racemic mixture (50:50) of its two enantiomers, Levobupivacaine, S (-) isomer and Dextrobupivacaine, R (+) isomer. Severe Central Nervous System (CNS) and cardiovascular adverse reactions reported in the literature after inadvertent intravascular injection or intravenous regional anaesthesia have been linked to the $\mathrm{R}(+)$ isomer of Bupivacaine. Levobupivacaine contains a single enantiomer of bupivacaine hydrochloride belonging to the family of $n$ alkyl substituted pipecoloxylidide. It is chemically described as (S)-1-butyl-2-piperidylformo-2', 6'-xylidide hydrochloride and it is related chemically and pharmacologically to the amino amide class of local anaesthetics. ${ }^{3}$

Ropivacaine is a new long-acting local anaesthetic drug belonging to the amino amide group. Though it was synthesised by Ekenstam in 1957 and belongs to the same group as that of bupivacaine and mepivacaine, pipecoloxylidides local anaesthetics, Ropivacaine was introduced to clinical practice in 1996. Ropivacaine is shown to be effective for subcutaneous infiltration, epidural, 
intrathecal and peripheral nerve block, obstetrics and postoperative analgesia. 4,5 Ropivacaine and Levobupivacaine, both being S-enantiomers of Bupivacaine have similar duration of sensory and motor blockade as racemic Bupivacaine, but having safe cardiovascular profile. Levobupivacaine (S-1-butyl-2-piperidylformo-2', 6'-xylidide hydrochloride) is the pure $S(-)$ enantiomers of racemic Bupivacaine. Because of its significantly decreased cardiovascular and central nervous system toxicity and its relative potency ratio with racemic Bupivacaine being 0.98:1, Levobupivacaine also seems to be an attractive alternative to Bupivacaine. As Levobupivacaine and Ropivacaine have been recently ${ }^{6}$ introduced in India, not many studies have been done in India comparing the use of isobaric Levobupivacaine $0.5 \%$ and isobaric Ropivacaine $0.5 \%$ for spinal anaesthesia. Hence, the present study was undertaken to compare the clinical efficacy of these two drugs for Spinal anaesthesia.

The current gold standard surgical treatment for Benign Prostatic Hyperplasia (BPH) is 7 transurethral Resection of Prostate (TURP). TURP is the $2^{\text {nd }}$ most common procedure in men over 65 years of age. BPH affects $50 \%$ of males at 60 years and $90 \%$ of 85 -year-olds, so TURP is most commonly performed on elderly patients, a population group with a high incidence of cardiac, respiratory and renal disease. TURP carries unique complications because of the need to use large volumes of irrigating fluid for the endoscopic resection. 8 Regional anaesthesia is the technique of choice for TURP. Addition of intrathecal opioids as adjuvants to local anaesthetics will reduce the dose of ${ }^{9,10}$ local anaesthetics and provide profound analgesia without affecting the level of blockade, which is important for TURP surgeries. Fentanyl because of its short duration and faster onset of action is added as adjuvant in both the groups to maintain uniformity.

\section{MATERIALS AND METHODS}

Regional anaesthesia is preferred for over general anaesthesia in transurethral resection of prostate, because of the following advantages: 1 . Allows monitoring of mentation and early signs of TURP syndrome and bladder perforation, 2 . Promotes peripheral vasodilation reducing circulatory overload, 3. Reduces blood loss, requiring fewer transfusions, 4. Avoids effects of general anaesthesia on pulmonary pathology, 5. Good postoperative analgesia, 6. Reduced incidence of postoperative deep vein thrombosis/pulmonary embolism and 7. Neuroendocrine and immune response are better preserved and lower cost. The study population included 88 elderly male patients of ASA I, II or III undergoing transurethral resection of prostate, who gave a valid consent. Simple random sampling technique was adopted; 88 continuous patients posted for BPH surgery in King George Hospital were included in the study. The first case was included in Group B and the second case in Group R. This procedure was continued till the required sample size of 88 was achieved. In each group, the dose used for the first patient was $8 \mathrm{mg}$. For each subsequent patient, the dose was determined by the outcome of the previous patient in the group with the dosing increment set at $1 \mathrm{mg}$. Successful anaesthesia was considered if a bilateral sensory block to the T12 dermatome was attained within 20 mins after intrathecal injection and surgery was completed or proceeded until at least 50 mins after the intrathecal injection without epidural supplementation. After successful anaesthesia, the dose of the study drug for the next patient was decreased by $1 \mathrm{mg}$ in that group. Conversely, if a failure was recorded, the dose of the study drug for the next patient was increased by $1 \mathrm{mg}$ in that group.

Group B - Received $2.5 \mathrm{~mL}$ of 11 isobaric $0.5 \%$ Levobupivacaine plus Fentanyl 25 mcg intrathecally.

Group R - Received $2.5 \mathrm{~mL}$ of isobaric $0.75 \%$ Ropivacaine plus Fentanyl 25 mcg intrathecally.

Fentanyl when used as an adjuvant for spinal anaesthesia has a local anaesthetic sparing effect with profound and prolonged analgesia without significantly affecting the level of blockade, which is important in TURP surgeries. It is a randomised controlled study in which characteristics like onset, duration, maximum level of sensory and motor block, haemodynamic parameters like heart rate, systolic and diastolic blood pressures and mean arterial pressure were recorded. Side effects if any were recorded. The information collected regarding all the selected cases were recorded in a Master Chart. Data analysis was done with the help of computer using Epidemiological Information Package (EPI 2010) developed by Centre for Disease Control, Atlanta.

\section{RESULTS}

\section{Demographic Data}

The mean age of the patients in Group $\mathrm{R}$ was $67.2 \pm 8.6$ years, while in Group B it was $64.2 \pm 7.7$ years and were comparable in both groups and was not significant statistically ( $p-0.0812$ ). The mean height of the patients were 159.5 \pm 8.0 $\mathrm{cm}$ and $160 \pm 8.7 \mathrm{~cm}$ in Group R and Group B respectively and were comparable in both groups and was not significantly statistical (p-0.5593). The mean weight of the two groups were similar, while in Group $\mathrm{R}$ it was $62.8 \pm 7.2 \mathrm{~kg}$ and in Group B it was $62.9 \pm 8.9 \mathrm{~kg}$ and were comparable in two groups and was not statistically significant ( $p-0.9895)$. The ASA physical status distribution was comparable in two groups. In Group R 19, 19 and 6 patients belonged to ASA 1, 2 and 3 respectively, while in Group $B$ the number of patients belonging to ASA 1, 2 and 3 were 22, 18 and 4 respectively.

\section{Duration of Surgery and Irrigation Fluid}

The mean duration of surgery in Group $\mathrm{R}$ was $41.4 \pm 8.6$ minutes, while in Group B it was $42.6 \pm 7.9$ minutes when compared between two groups is not statistically significant. The mean of irrigation fluids used were $5.98 \pm 1.56$ litres and $6.23 \pm 1.44$ litres in Group R and Group B respectively and not statistically significant.

\section{Onset and Regression of Sensory Block}

Onset of sensory blockade at T10 dermatome was achieved by $6.0 \pm 1.71$ minutes in patients in Group $\mathrm{R}$ and $5.57 \pm 1.34$ minutes in patients of Group B. This was not clinically or statistically significant. All the patients attained a level of T10 sensory blockade in both the groups. All patients achieved a sensory block of T10 dermatome, which was sufficient for surgery. Highest level of block achieved in Group R was T6 in $50 \%$ of the patients compared to $\mathrm{T} 6$ in $47.7 \%$ of patients in Group B. There is no statistically significant difference between the two groups.

Time from injection to two dermatomal regression was $112.7 \pm 21.3$ minutes in Group $\mathrm{R}$ and $129.9 \pm 15.7$ minutes in Group B, when compared it was found to be highly significant statistically with a $\mathrm{p}$ value of $<0.001$. 
When the time required for sensory level to regress below T10 dermatomal level was studied. It was found to be $174.8 \pm 16.6$ minutes for Group R and $178.7 \pm 16.6$ minutes for Group B, which was statistically not significant as $p$ value was 0.1 ( $p>0.05$ NS).

\section{Onset and Duration}

The mean time required for the onset of Bromage score of 1 in patients belonging to Group $\mathrm{R}$ was $6.34 \pm 1.68$ minutes, while that for patients in Group B was $4.61 \pm 1.32$ minutes. The results were clinically and statistically highly significant with $p$ value of $<0.001$.

The mean duration of motor block in Group B patients was $196.6 \pm 17.7$ minutes, while that of Group $\mathrm{R}$ was $135.3 \pm 24.8$ minutes, which was statistically highly significant as $\mathrm{p}$ value was $<0.001$.

The mean duration of complete motor block in Group $\mathrm{R}$ patients was $111.8 \pm 17.3$ minutes, while that of Group B was $168.2 \pm 17.2$ minutes, which were clinically and statistically highly significant as $p$ value was $<0.001$ (Table 1 ).

Incidence of nausea and vomiting was comparable between the two groups. There was no incidence of post- dural puncture headache, transient neurological symptoms in either of the two groups.

\section{Time from Injection to Two Dermatomal Regressions}

Luck JF and Colleagues observed that the times of sensory block regression, both to T10 [Bupivacaine 129 mins (58 178 mins), levobupivacaine 131 mins (50 - 205 mins) and Ropivacaine 84 mins (45 - 145 mins)] and complete regression were shorter in the Ropivacaine group than other two groups. We also observed that two dermatomal regressions with Ropivacaine were faster compared to levobupivacaine and this matches well with results of abovementioned study.

\section{Time to Regression of Sensory Block to Below $\mathbf{T}_{\mathbf{1 0}}$}

Breebart et al compared $10 \mathrm{mg}$ levobupivacaine and $15 \mathrm{mg}$ Ropivacaine for outpatient knee arthroscopy and reported L2 regression of sensory block after 173 mins and 167 mins with home discharge after 311 mins and 305 mins respectively. In our study, time to regression of sensory block to T10 was 178.7 and 174.8 in levobupivacaine which was comparable to above study (Table 1).

\begin{tabular}{|c|c|c|c|c|c|c|}
\hline \multicolumn{2}{|c|}{ Group R } & \multicolumn{4}{c|}{ Group B } \\
\hline Parameter & Mean & SD & Mean & SD & Mean Difference & P value, Significance \\
\hline Sensory Block at T10 (Min) & 6.0 & 1.71 & 5.57 & 1.34 & 0.43 & 0.1907 , Not Significant \\
\hline 2 Dermatomal Regression (Min) & 112.7 & 21.3 & 129.9 & 15.7 & 17.2 & $<0.0001$, Significant \\
\hline Regression of Sensory Block to below T10 (Min) & 174.8 & 16.6 & 178.7 & 16.6 & 3.9 & 0.2752 , Not Significant \\
\hline Bromage Scale 1 (Min) & 6.34 & 1.68 & 4.61 & 1.32 & 1.73 & $<0.0001$, Significant \\
\hline Duration of Motor Blockade (Min) & 135.3 & 24.8 & 196.6 & 17.7 & 61.3 & $<0.0001$, Significant \\
\hline Duration of Complete Motor Blockade (Min) & 111.8 & 17.3 & 168.2 & 17.2 & 56.4 & $<0.0001$, Significant \\
\hline
\end{tabular}

Table 1. Comparison of Sensory and Motor Block Characteristics

\section{DISCUSSION}

Subarachnoid block is commonly employed regional anaesthetic technique for performing transurethral resection of prostate. It provides adequate anaesthesia for the patient and good relaxation of the pelvic floor and the perineum for the surgeon. The signs and symptoms of water intoxication and fluid overload can be recognised early, because the patient is awake. Accidental bladder perforation is also recognised easily if the spinal level is limited to T10, because the patient experiences abdominal or shoulder pain. Satisfactory regional anaesthesia for TURP involves achieving block level that interrupts sensory transmission from the prostate and bladder neck.

Bupivacaine remains one of the most popular local anaesthetic agents because of its high potency and minimal neurological symptoms, but caution is required because of its toxicity profile particularly to the cardiac. Though 12 cardiotoxicity is not of concern in subarachnoid blockade, the quality of sensory blockade, duration of motor blockade, haemodynamic changes and side effect profile are some consideration in selecting a drug for spinal anaesthesia.

Levobupivacaine and Ropivacaine, pure S-enantiomers of bupivacaine are safer alternative for regional anaesthesia than its racemic parent with lower cardiotoxicity. The sensory and motor block characteristics of 13 intrathecal Ropivacaine and Levobupivacaine are found to be inconsistent in various studies and the findings differ with varying doses of drug used in different studies.

\section{CONCLUSION}

From the present study, it can be concluded that the onset of sensory block and the maximum sensory block were achieved earlier with intrathecal $0.5 \%$ Isobaric Levobupivacaine $(12.5$ $\mathrm{mg})+$ Fentanyl $25 \mu \mathrm{g}$ combination than with $0.75 \%$ isobaric Ropivacaine $(18.75 \mathrm{mg})+$ Fentanyl $25 \mu \mathrm{g}$ combination. The maximum level of sensory blockade achieved was equal with Levobupivacaine and Fentanyl combination than with Ropivacaine and Fentanyl combination. Two segment regression times were faster with Ropivacaine and Fentanyl combination. Duration of sensory blockade was prolonged with Levobupivacaine and Fentanyl combination. Onset of motor block and achieving complete motor block were faster with Levobupivacaine plus fentanyl combination and complete motor block was obtained in higher number of patients in this group. Duration of motor block was shorter with Ropivacaine plus Fentanyl combination. The differences between the groups regarding the above sensory and motor block parameters were statistically significant. The haemodynamic changes observed in both the groups were similar; $0.5 \%$ isobaric Levobupivacaine $(12.5 \mathrm{mg})$ and Fentanyl (25 mcg) combination produced faster onset, prolonged and higher level of sensory blockade, prolonged duration of motor blockade compared to $0.75 \%$ isobaric Ropivacaine (18.75 mg) and Fentanyl (25 mcg) combination in adult patients undergoing transurethral resection of prostate surgeries without significant haemodynamic changes. Hence, ${ }^{12}$ Ropivacaine and Fentanyl combination can be a better drug for TURP surgeries compared to Levobupivacaine and Fentanyl combination. 


\section{REFERENCES}

[1] Henderson DJ, Faccenda KA, Morrison LM. Transient radicular irritation with intrathecal plain lignocaine. Acta Anaesthesiol Scand 1998;42(3):376-8.

[2] Glaser C, Marhofer P, Zimpfer G, et al. Levobupivacine versus racemic bupivacaine for spinal anesthesia. Anesth Analg 2002:94(1):194-8.

[3] Hansen TG. Ropivacaine: a pharmacological review. Expert Rev Neurother 2004;4(5):781-91.

[4] Kallio H, Snall EV, Kero MP, et al. A comparison of intrathecal plain solutions containing ropivacaine 20 or $15 \mathrm{mg}$ versus bupivacaine $10 \mathrm{mg}$. Anaesth Analg 2004;99(3):713-7.

[5] Mantouvalou M, Ralli S, Arnaoutoglou H, et al. Spinal anaesthesia: comparison of plain ropivacaine, bupivacaine and levobupivacaine for lower abdominal surgery. Acta Anaesthesiol Belg 2008;59(2):65-71.

[6] Agarwal A, Verma RK, Srivastava S. Ropivacaine: the latest local anaesthetic in the Indian market. J Anaesth Clin Pharmacol 2010;26(2):223-8.

[7] Vanna O, Chumsang L, Thongmee S. Levobupivacaine and bupivacaine in spinal anesthesia for transurethral endoscopic surgery. Journal Medical Association of Thailand 2006;89(8):1133-9.
[8] Markham A, Faulds D. Ropivacaine. A review of its pharmacology and therapeutic use in regional anaesthesia. Drugs 1996;52(3):429-49.

[9] Roberts PC, Brown BR. Local anaesthetic pharmacology. International practice of anaesthesia 1st edn. Oxford: Butterworth-Heinemann 1996.

[10] Whiteside JB, Wildsmith JA. Developments in local anaesthetic drugs. Br J Anaesth 2001;87(1):27-35.

[11] Sell A, Olkkola KT, Jalonen J, et al. Minimum effective local anaesthetic dose of isobaric Levobupivacaine and Ropivacaine administered via a spinal catheter for hip replacement surgery. Br J Anaesth 2005;94(2):239-42.

[12] Leone S, Di Cianni S, Casati A, et al. Pharmacology, toxicology and clinical use of new long acting local anesthetics, ropivacaine and levobupivacaine. Acta Biomed 2008;79(2):92-105.

[13] Gautier P, De Kock M, Huberty L, et al. Comparison of The effects of intrathecal ropivacaine, levobupivacaine and bupivacaine for caesarean section. Br J Anaesth 2003;91(5):684-9. 